\title{
The Extent of Adoption of e- Publishing by University Presses in Kenya
}

Michael S. Wafula, Joseph J. Musakali and Joseph W. Muliaro

\section{Introduction}

1 Publishing refers to the act of selecting, producing and disseminating documents or literary works such as books, newspapers, magazines, tabloids and much more to a large audience. In a traditional sense it involves the distribution of printed works. Seemingly, there is a shift in technological approaches in the way publishing is done. Conversely, with $21^{\text {st }}$ entury, many publishing houses are engaging in electronic publishing as a complementary to traditional publishing.

2 According to Peek, R.P and Newby, B.N (1996), Electronic publishing is not necessarily bound by any traditions. With precision, Chennupati, Schubert and Heng (2006) argue that it refers to the application of computing software by a publisher to information content created and packaged for a specific audience, and the distribution of the final product through electronic means.

3 The term "electronic publishing" can be interpreted in many different ways. As such, publishing is an integrated process aimed at providing information in different quantities and with different qualities to different categories of end-users (Ramaiah et al. 2006). It can also extend to be a networking support to collaborative authorship and electronic communication among authors, editors, referees, and other participants in the publishing process. Since "publishing" implies production and distribution, however, the term refers most obviously to the generation of publications in electronic form or, at least, with the aid of electronics (Lancaste 1995).

4 The personal computer has revolutionized communication, and digitized text has introduced a radically new medium of expression (Hanham 1993). Moreover, these 
medium of expression are in form of e-resources such as CD-ROMs, DVDs, websites, networks and blogs.

\section{Types of publishing}

5 Steven (2018) categorizes publishers as traditional or commercial and self-publishers. In traditional royalty publishing, the publisher screens books for quality and marketability and then, at its cost, handles editing, manufacturing, marketing, promotion, sales, warehousing, and fulfillment. The author receives a royalty on sales. The self-publisher, by contrast, undertakes all of these tasks at his/her own cost, but keeps all revenue.

Printwiki argues that "desktop publishing" was coined in the mid-1980s by Paul Brainerd, the founder of Aldus Corporation. Essentially, the idea of publishing from one's desktop was to increase output quality resulted in many publications. Initially, desktop publishing was used for little more than short-run newsletters, flyers, and brochures, the same systems are now often used to create books, slick magazines, and newspapers. Most publishers in the institutions of higher learning practice this type of publishing.

\section{Research Methodology}

7 This paper adopted research survey design. Survey is a technique of gathering information by questioning participants or respondents as subjects of a research and who belong to a representative sample, through standardized procedures with an aim of studying relationships among variables (Corbetta 2003). Surveys allow the collection of a large amount of data from a sizeable population in a highly economical way. Often obtained by using a questionnaire administered to a sample, these data are standardized, allowing easy comparison (Saunders et al. 2009).

Mixed methods research is an approach to inquiry that combines or associates both qualitative and quantitative forms. Thus, it is more than simply collecting and analyzing both kinds of data (Creswell 2009). This paper used mixed method approach where data collected and simple descriptive statistical analysis was done based on objectives of the study to gauge the relationships between variables.

\section{Population of the study}

The sample frame of 49 accredited universities in Kenya was used as shown in Table 1. These gave the researchers a well distribution of institutions at multiple levels found in Kenya whether religious, government, or foreign sponsored. Ambira (2008) describes a study population as the complete set of individuals, cases or objects with some common observable characteristics. In agreement Sunders et. Al., (2009) state that the full set of cases from which a sample is taken is called the population. In sampling, the term 'population' is not used in its normal sense, as the full set of cases need not necessarily be people.

The table below shows the study population of 49. It shows that 31 universities are public funded while 18 are privately funded universities operating in Kenya. These are institutions mandated to impart, create and disseminate knowledge, embrace world trends and a link to global stage. 
Table 1: Study Population

\begin{tabular}{|l|l|}
\hline Participant & Population \\
\hline Public funded Universities & 31 \\
\hline Privately funded Universities & 18 \\
\hline Total & 49 \\
\hline
\end{tabular}

\section{Sample of the study}

11 Judgmental sampling was used in selecting key participants under the study was ideal. The key participants the researchers used were 6 universities with presses that were known and therefore, they were reliable source of information. Purposive sampling is also known as judgmental, selective, or subjective sampling. What is more to this type of technique is according to Saunders, Lewis, \& Thornhill, (2009:237) that, "it enables researcher to use his/her judgment to select cases that will best facilitate to answer research question(s) and to meet their objectives." Patton (1990) states that the 'logic and power of purposeful sampling lies in selecting information-rich cases for study in depth. The study sampled six (6) universities which were information-rich in doing academic publishing as a representation of academic fraternity.

12 Table 2 below shows the study sample that comprised six (6) university presses indicating affiliation or sponsor and type of press. The table infers that the majority of university presses are public funded. However, only one was a printing press while the rest were publishing presses. Among the two privately funded institutions, one was a publishing printing press. Therefore, majority of Kenyan University presses were publishers.

Table 2: Study Sample

\begin{tabular}{|l|l|l|}
\hline Participant & Sponsor & Type of press \\
\hline University of Nairobi Press & Public & Publishing \\
\hline Moi University Press & Public & Publishing \\
\hline Kenyatta University Press & Public & Printing \\
\hline Egerton University Press & Public & Publishing \\
\hline Strathmore University Press & Private & Publishing \\
\hline Catholic University of Eastern Africa & Private & Publishing Printing \\
\hline
\end{tabular}




\section{Analysis of Data}

Data collected was analyzed quantitatively using simple descriptive statistics. Data analysis is the process of creating order, structure and meaning to the mass of information collected (Mugenda 2003).

Data was analyzed and summarized accordingly. Statistical techniques were employed in analyzing data. Quantitative data obtained from questionnaires was presented by use of tables showing numerical data and symbolic representations like bar graphs.

\section{Research Instruments}

15 A questionnaire was one of the instruments used in this study that had closed and opens ended questions for the participants to answer. Also document analysis was done by visiting key informants' website to retrieve more content. Documentary secondary data are often used in research projects that also use primary data collection methods. However, you can also use them on their own or with other sources of secondary data, for example for business history research within an archival research strategy (Saunders et al. 2009).

\section{Data gathering procedure}

16 After pre-testing the questionnaire, the researchers sought the permission to collect data from the presses. Personal visit were among ways in which the researchers distributed the questionnaires while others were distributed via electronic mail. The questionnaire had open-ended and closed-ended questions.

\section{Findings of the study}

\section{Identify institutions that practice academic publishing in Kenya}

17 It was discovered that many institutions of higher education in Kenya are at the infant stage and had challenges engaging in electronic publishing. Besides, most of them have Desktop Publishing Units (DTP) that do typesetting, layout and design. Conversely, most of established presses engaged in print publications such as books, Journals and magazines. It was discovered that out of the 49 accredited Institutions of higher education in Kenya, only 6 universities have presses. Moreover, what distinctively came to the fore was that, Moi University Press, University of Nairobi Press, Strathmore University Press and Egerton University Press are publishing presses while Kenyatta University Press is printing press, and Catholic University of Eastern Africa is a publishing printing press. Some universities published through established university presses; on the other hand, others outsourced private or commercial publishing printing presses in doing their publications.

It was bare that publishing presses outsourced their printing services through a competitive tendering process. Since the two published books and had no printing press, it was inevitable for them to subcontract printing services with prequalified commercial printers. However, it was discovered most printing presses did copies of paperbacks and 
e-Publication was the underlying future venture, since the world was embracing the technology.

On the other hand, most of the academic publishers articulated that e-publishing has a bright future. Based on these phenomenon university presses found it a difficult venture when the authors express disapprovals owing to digital rights management and fear of unknown. In addition, the challenge with reading online was stated as a culture not embraced among potential readers exacerbated by poor online marketing and internet access.

Despite the lucrative market, most university presses had specific publishing areas in which they ventured in; accordingly, they adhered to scholarly publishing as outlined by their respective policies. Consequently, it became bare that on average these presses published 3 publications annually.

\section{The relationship between authors' knowledge on e-publishing platforms and publishers' choice of the e-platforms}

21 When it came to the relationship between authors' knowledge on e-publishing platforms and publishers' choice of the e-platforms, they varied from one press to the other.

To some it was a rare encounter when it came to authors with knowledge on formats in which they would want their publications as end products. Quite often than not, authors depended on publishers' expertise in determining the publication formats. Conversely, those with information on the kind of formats were few and it did also add up on the relevance of format choices for those who ventured. This implied that there was no relationship between authors' knowledge and publishers' choice of publication. It was discovered that most authors were not privy to e-formats.

There were however, some authors who were privy to various formats, and engaged with the publisher on its significance before settling on any as final products. It emerged that most discussions between the authors and the publishers yielded many if not all would want both print and e-formats; but first, print was the priority then e-pub. Ostensibly, most of publishers had portable document format (pdf) as a dominant e-format. Basically, majority of authors preferred this format as it retained the book format.

Expressively, most e-pub products published were marketed through third party publishers known as aggregators. Uploaded on publishers' websites, many faced policy challenges where honorarium to authors and autonomy to make decisions regarding funds were among impediment issues. 
Fig. 1 showing the \% rate on authors' knowledge on e-publishing platforms and publishers' choice of the e-platforms

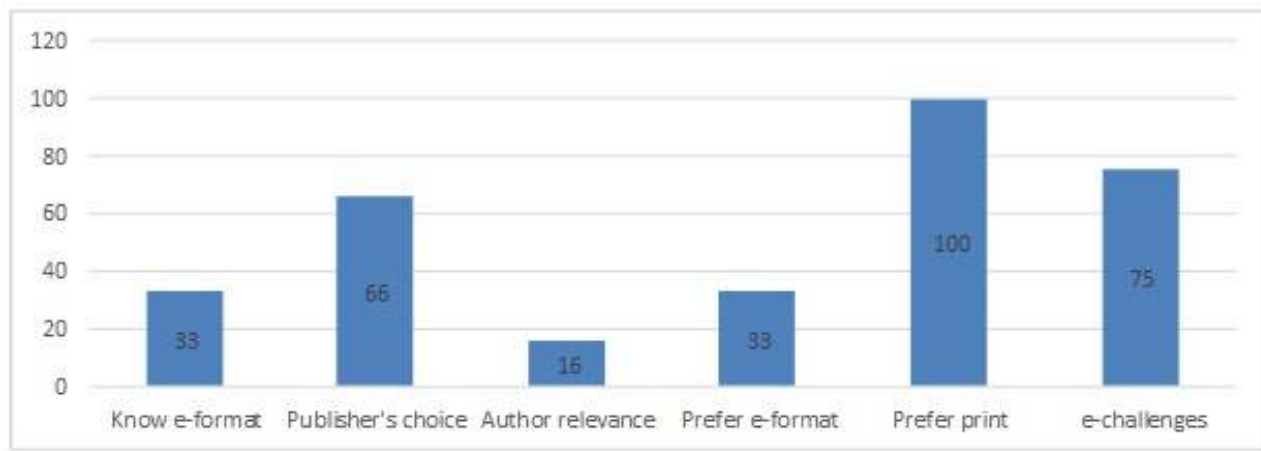

\section{Existing work relationship between the publisher and an author influences the format of a publication}

The study revealed that in some cases authors felt they had enough information and this had an effect on the publication format. Often, authors articulated ownership of the publication and thus, knew what they wanted. This however, was not expressed across the presses but except a few. It was discovered that authors demonstrated no need of information on publishing except the format they were focused on especially print.

Equally, it was noted that authors' request for advice on publication formats was not frequent. It meant that publishers' effort to stimulate authors about e-format was construed to expose them on challenges; particularly in acquiring an e-reader, procedures in aggregator's contracts, pay system, and electronic marketing. This process was deemed tedious and could limit their publications as opposed to traditional distribution and access.

Fig. 2 showing the \% rate on work relationship between the publisher and author influence on the format of a publication

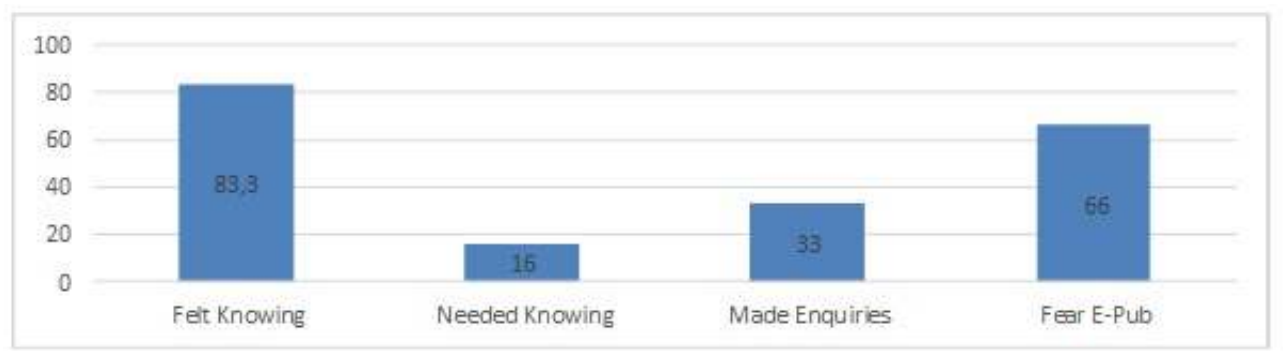

\section{Whether or not there is an association between levels of staff experiences within publishing and e-publishing}

It was revealed that the levels of staff experience within the field of publishing had a bearing on the technological knowledge a publisher possessed. Most of the employees who had 20 years and above working in press possessed technological knowledge on epublishing. However, those found to have worked below 7 years had little knowledge on 
e-publishing. It was revealed that very few publishers are trained on digitization of content.

Though publishers alluded to the benefits of e-publishing, the study showed that only a small percentage $12.2 \%$ of the Kenyan academic publishers had established presses. $87.8 \%$ of universities indirectly engaged in e-publishing. Significantly, they had e-repositories on their websites and are likely to start e-publishing in the near future. For those who were publishing with printing presses, represented $2.0 \%$ of universities.

Fig. 3 showing the \% rate of whether or not there is an association between levels of staff experiences within publishing and e-publishing

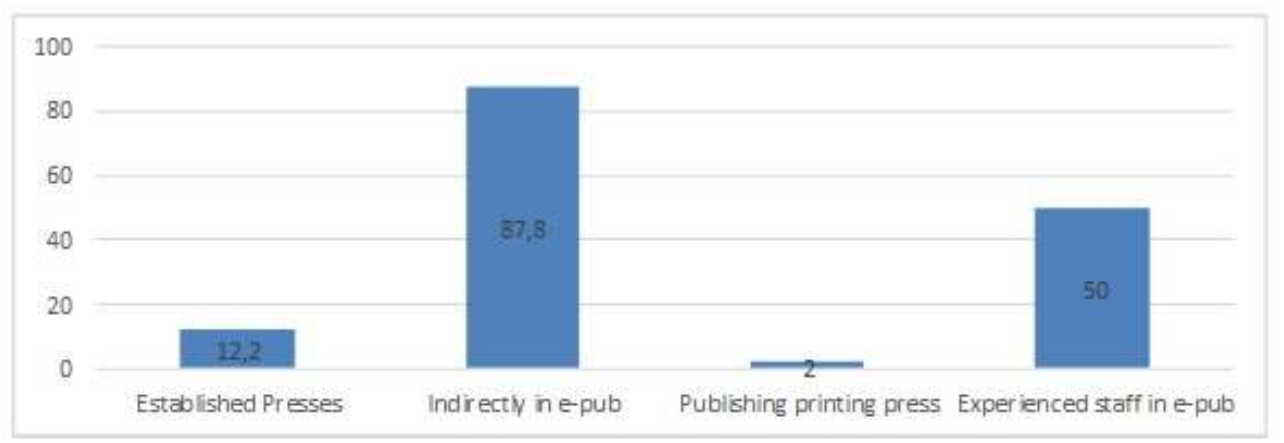

\section{Conclusion}

In conclusion, the study established that different university presses were in different levels of e-publishing adoption. Most authors had little or no knowledge on e-formats and relied on the choice of the publishers and/or advice. A small percentage of authors were privy to various existing e-formats and used this knowledge to engage the publishers before settling on a preferred choice. Some authors had limited knowledge on particular formats and were rigid in adopting alternative formats. Additionally, staff working in presses had a lot of influence on the choice of formats as the study established that those who had longer working experiences had substantial knowledge of e-publishing as compared to those who had short stints in employment. This was enhanced by the fact that only a small percentage of Kenyan academic publishers had established presses. Most universities' closest interaction with e-publishing was through e-repositories established mainly in their libraries or websites where e-collections of theses and dissertations were commonplace as well as academic publications by resident faculty published elsewhere.

The researchers therefore conclude that there is need to create more e-publishing awareness among academic institutions through seminars, collaborations as well as engaging staff in training opportunities through refresher courses. It is imperative for writing workshops on importance of e-publishing, types of eBooks, formats, e-Readers and exhibitions to expose authors, staff and other stakeholders to e-publishing technologies. In efforts to accelerate or realize e-adoption, the researchers recommend training of authors and publishers on importance of electronic marketing, e-Business, digital rights management, profits, pay-systems and costs, digitization of content and distribution for global market access. 


\section{BIBLIOGRAPHY}

\section{References}

Ambira, C. 2010. Records Management and Risk Management at Kenya Commercial Bank Limited, Nairobi Area. Eldoret: Moi University.

Creswell, J.W. 2009. Research Design: Qualitative, Quantitative, and Mixed Methods Approaches. 3rd ed. SAGE Publications Ltd.

Hanham R. 1993. The Electronic Word: Democracy, Technology, and the Arts. Retrieved 13 March 2019. https://www.press.uchicago.edu/ucp/books/book/chicago/E/bo3661152.html.

Lancaster, F. W. 1995. “The Evolution of Electronic Publishing.” LIBRARY TRENDS 43, no. 4

(Spring): 518-527. Retrieved 13 March 2019 https://

pdfs.semanticscholar.org/3abd/9d8450b42be0870d27cf3d93cb7339b5dc02.pdf.

Law Offices of Daniel N. Steven, LLC “What is Self-publishing?" publishlawyer.com. Retrieved 13 March 2019. http://publishlawyer.com/publishing-faq/\#Q_What_is_self-publishing

Mugenda, O. M., and A. G. Mugenda. 1999. Research Methods: quantitative \& qualitative approaches. Nairobi, Kenya: Acts Press.

Patton, M. Q. 1990. Qualitative Evaluation \& Research Methods, 2nd ed. Newbury Park, California: Sage Publication.

Peek, Robin P., and Gregory B. Newby. 1996. "Introduction,” In Scholarly Publishing: The Electronic Frontier, edited by Robin P. Peek and Gregory B. Newby, xv-xxii. Cambridge: MIT Press.

Printwiki. Retrieved 12 March 2019. http://printwiki.org/Desktop_Publishing.

Ramaiah, Chennupati K., Schubert Foo, and Heng Poh Choo. 2006. "Trends in Electronic Publishing." In ELearning and Digital Publishing, edited by Hsianghoo Steve Ching, Paul W. T. Poon, and Carmel McNaught, 111-131. Computer Supported Cooperative Work. Dordrecht: Springer Netherlands. https://doi.org/10.1007/1-4020-3651-5_7.

Saunders, M., P. Lewis, and A. Thornhill. 2009. Research methods for business students. 5th ed. United Kingdom: Pearson.

\section{ABSTRACT}

Knowledge creating and dissemination is synonymous with institutions of higher learning. However, many institutions, especially in Africa spurn electronic publishing (e-publishing), failing to join most parts of the world that have embraced it with very positive results. Though connected to internet and the World Wide Web, only a number of universities practice electronic publishing. This paper aims to study the electronic publishing trends in institutions of higher learning and identify the opportunities and challenges faced by academic publishers in Kenya. The objectives of the study are to: identify institutions that practice academic publishing in Kenya; examine the relationship between authors' knowledge on e-publishing platforms and 
publishers' choice of e-platforms; analyze whether an existing work relationship between the publisher and an author influences the format of a publication; examine whether or not there is an association between levels of staff experiences within publishing and e-publishing. This is a research survey that employed a mixed method approach. The sample frame of 49 universities was used. Judgmental sampling was used in selecting key participants under the study. Data were collected by questionnaires and document analysis where simple descriptive statistical analysis was done based on objectives of the study to gauge the relationships between variables. Findings of the survey show that $12.2 \%$ of the Kenyan academic publishers are engaged in e-publishing and established presses. $87.8 \%$ of universities indirectly engaged in e-publishing with the option of owning a press/DTP unit. Significantly, they had e-repositories on their websites and are likely to start e-publishing in future. Most of them feel that e-publishing has a bright future. Experiences challenge with online reading cultures, online marketing, Digital Rights Management (DRM) and poor internet access; lack of policy framework by publishers and/with authors on e-publishing. These reasons have hampered the introduction of e-publishing in universities' desktop publishing units (DTP) or presses. The study concludes that there is need to: create more e-publishing awareness among academic institutions; engage staff in training opportunities on e-publishing; create writing workshops and exhibitions to expose authors, staff and other stakeholders to e-publishing technologies to attract electronic adoption.

\section{INDEX}

Keywords: EPUB, DRM, DTP, e-Reader, e-Format

\section{AUTHORS}

\section{MICHAEL S. WAFULA}

Department of Moi University Press, School of Information Sciences, Moi University

mykstuma@gmail.com

\section{JOSEPH J. MUSAKALI}

Department of Publishing \& Media Studies, School of Information Sciences, Moi University

\section{JOSEPH W. MULIARO}

ICT Center of Excellence and Open Data (iCEOD), Jomo Kenyatta University of Agriculture \& Technology 